\title{
TORSION OF THE TESTIS AND ITS APPENDAGES DURING CHILDHOOD
}

\author{
BY \\ PETER JONES \\ From the Royal Children's Hospital, Melbourne, Australia
}

(RECEIVED FOR PUBLICATION JULY 24, 1961)

A painful testicular swelling accompanied by local signs and general symptoms constitutes a clinical picture in which the correct diagnosis is not always readily apparent. Proper management depends upon a knowledge of the possible causes, their relative likelihood and where possible their differentiation.

The aim of this report is to present the subjects as they occur in paediatric practice. The results of a prospective study of 19 children who presented with torsion of the testis or its appendages are recorded in detail. The findings illustrate some complexities and provide a sound basis for conclusions regarding the predisposing anatomical factors and the differential diagnosis. Although these have been appreciated for some time, it appears that they are not generally well known.

In order to provide a representative picture, a retrospective analysis has been made of 95 patients with acute conditions of the testis admitted to the Royal Children's Hospital in the decade 1950-1960.

\section{TORSION OF THE TESTIS}

To Delasiauve (1840) belongs the credit of the first clinical description of this condition. In a conversational style, rich with expletives and slightly scurrilous asides, he described his role as assistant in the treatment of extratunical torsion of an undescended testis in an adolescent, aged 15 years.

O'Conor $(1919,1933)$ noted that while 124 cases had been recorded before 1919, over 250 cases were reported between 1923 and 1930, the apparently increased incidence being presumably the result of wider recognition. This trend continues, but confusion and delay are still prevalent.

\section{Age Incidence}

Acute torsion of the testis has been reported in all ages from the newborn to the veteran in his seventh decade, but it is chiefly an affliction of children and adolescents. Ewert and Hoffman
(1944) concluded that the peak incidence lay in the age group 10-40 years. Evidence will be presented that the emergency may occur at any time during infancy and childhood.

\section{The Anatomy of Torsion}

Two types of torsion of the testis have been described: extratunical and intratunical.

Extratunical Torsion. In this type (Fig. 1c), also known as 'torsion of the spermatic cord' and 'supratunical torsion', the whole cord undergoes torsion around its long axis at a point proximal to the testis and tunica vaginalis. Delasiauve's original case appears to have been of this type.

Intratunical Torsion. The testis undergoes torsion around the last centimetre of the spermatic cord which is invested by the tunica vaginalis (Fig. 1b). This is by far the more common type.

\section{Mechanisms of Torsion}

Muscular exertions, vigorous or trivial, are known to usher in torsion, but of far greater importance are the predisposing anatomical factors which must exist. The following have been described:

(1) A spiral arrangement and low insertion of the fibres of the cremaster muscle.

(2) An abnormality of the junction of the epididymis with the testis, forming a 'mesorchium'.

(3) Loose areolar planes of fascia which surround the testis and the spermatic cord.

(4) A tunica vaginalis which extends proximally around the spermatic cord.

These will be considered in detail.

Cremaster Fibres. The evidence that these can act as a sole cause of torsion seems unconvincing; misinterpretation has possibly been due to the association with a high tunical investment. Muschat (1932), after careful consideration, including the construction of models, concluded that the cremasteric fibres were normally disposed in his patients, 

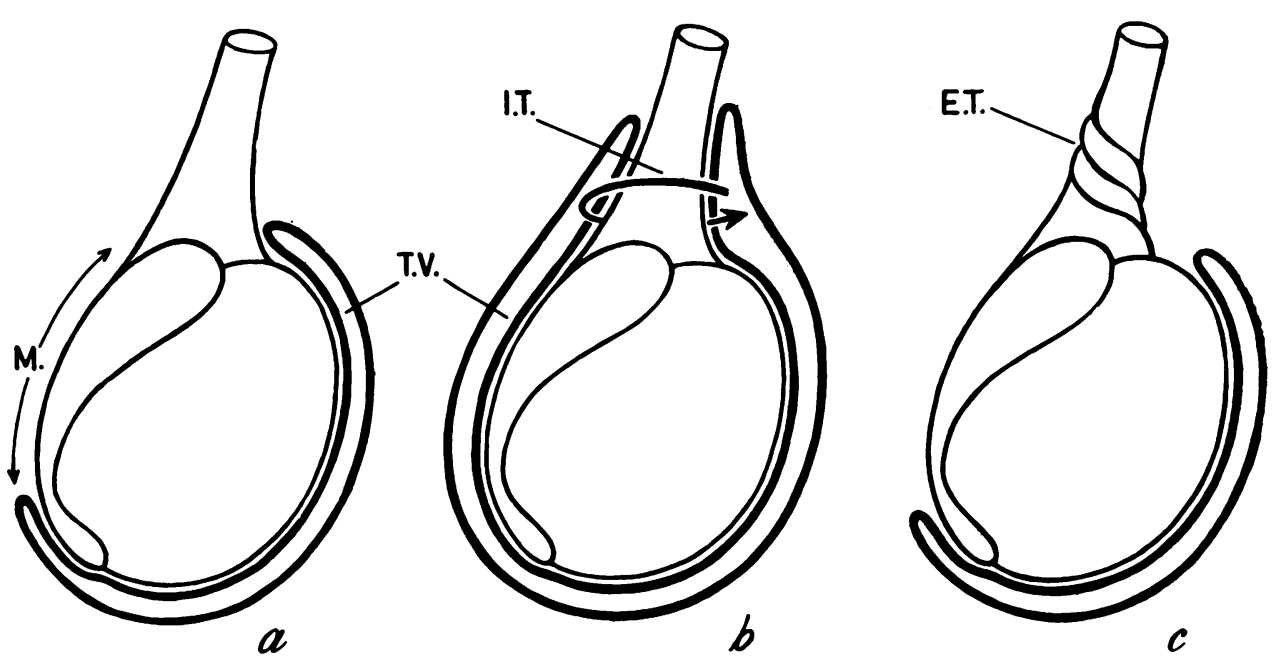

FIG. 1. - The extent and relationships of the tunica vaginalis (T.V.) in (a) normal testis. M.: extent of normal mesorchium; (b) intratunical torsion (I.T.); (c) extratunical (supratunical) torsion (E.T.).

but because of the accompanying high tunical investment the fibres were found inside the tunica at the site of torsion. This contradicts, and possibly corrects, the statement by O'Conor (1919) that cremaster fibres extended further down the spermatic cord in cases of torsion than in the normal.

The 'Mesorchium'. This term has been used in two ways. It is commonly applied to a thin linear attachment of the epididymis to the testis. The presence of this type of mesorchium may be important when torsion occurs between the testis and the epididymis (Williams, 1958). While this type of testis may be admitted as a contributory cause of torsion, it must be exceedingly rare. It has not been observed in the present series, or in that

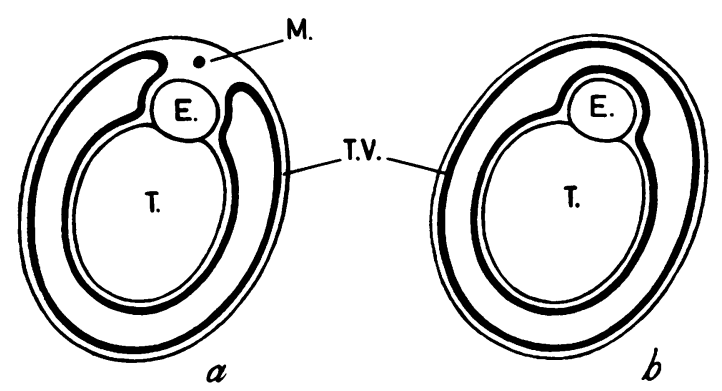

FIG. 2.-Horizontal section through testis (T.) and epididymis (E.) in (a) normal. M.: normal mesorchium; $(b)$ intratunical torsion. Note complete investment by tunica vaginalis (T.V.) (after Muschat). culled from the records of the Royal Children's Hospital.

'Mesorchium' is used in a second sense, connoting a 'mesentery' attached to the posterior aspect of the epididymis, and running vertically from the globus major to the globus minor (Fig. 1a and 2a). This arrangement is found in the normal testis, in which it acts as a stabilizing factor. Its absence (Fig. 2b) contributes significantly to torsion, as pointed out by Muschat (1932). In this sense the mesorchium was absent in every patient in this series. The testis was hanging free in the tunica, the original 'bell clapper testis', a term sometimes misapplied to that with the other type of 'mesorchium'.

Areolar Planes. The normal testis owes its relative immunity from external violence to its elusive mobility. This mobility could conceivably lead to torsion between the planes of areolar investment, and this must occur in extratunical torsion.

The existence of this form of torsion has been debated in the literature. Some deny that it occurs (Lowsley and Kirwin, 1944; Meltzer, 1926; Muschat, 1932), or maintain that trauma must coexist (Young and Davis, 1926). Nevertheless, the evidence in favour of extratunical torsion is incontrovertible (Delasiauve, 1840; Taylor, 1897; Abeshouse, 1936; Lambert and Smith, 1937; Ewert and Hoffman, 1944; Glaser and Wallis, 1954; Longino and Martin, 1955; Campbell, 1951; Peterson, 1961; Myers, 1961). 
However, it is apparent that extratunical (supratunical) torsion is much less common than the intratunical form. Extratunical torsion is usually found in infants, but it occasionally occurs in older children.

Tunica Vaginalis. In intratunical torsion the parietal tunica vaginalis extends proximally to invest the terminal 2 to $6 \mathrm{~cm}$. of the spermatic cord with a serosal sleeve (Fig. 1b) and this, together with the absence of a posterior mesorchium, sets the stage for torsion.

\section{The Site of the Testis}

O'Conor (1933) and Ewert and Hoffman (1944) thought that half of the reported cases of the torsion had occurred in undescended testes. Opposed to this view is the undoubted preponderance of fully descended testes in both series reported here.

The phenomenon of 'testis redux' has probably contributed to the incorrect assumption that a testis was incompletely descended at the onset of torsion, when in fact the apparent lack of descent was an effect of the torsion.

Testis Redux. When a normally descended testis is subjected to torsion, it can be drawn upwards to reach the pubic tubercle, or even to lie in the superficial inguinal pouch (Rigby and Howard, 1907; Allen and Andrews, 1940; Ewert and Hoffman, 1944; Burkitt, 1956).

Little has been written about the mechanisms responsible, but a sustained reflex contraction of the cremaster muscle fibres could readily produce upward displacement of the testis. In childhood almost all normal testes are 'retractile', i.e. capable of moving into the superficial inguinal pouch (Browne, 1938; Jones, 1958). It is emphasized that 'testis redux' is not solely dependent on extratunical torsion (torsion of the spermatic cord as a whole) with a consequent 'winding up' effect. Although this event could theoretically produce redux, upward displacement of the testis was not observed in any of the five cases of extratunical torsion in the Royal Children's Hospital series.

\section{TORSION OF THE VESTIGIAL APPENDAGES}

\section{Historical Aspects}

Giovanni Battista Morgagni was professor of surgery in Padua for over 50 years and published his many observations on surgical pathology in De Sedibus et Causis Morborum in 1761. Eight years later an English translation by Benjamin
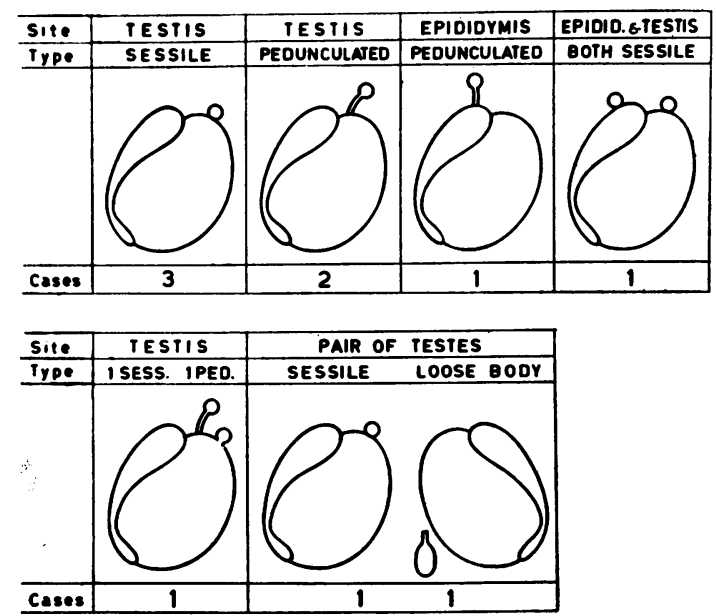

FIG. 3.-Diagrammatic reconstruction of Morgagni's original descriptions of the findings in 10 testes.

Alexander was printed in London (Alexander, 1769)*. The presence of frozen loculi in a hydrocele dissected in February 1745 testified to the rigours of winter in the Venetian plain. A cold outhouse may well have been suitable for painstaking dissections occupying several days at a time when preservation of cadavers was perhaps not well established.

No illustrations accompanied Morgagni's descriptions, but Alexander's endearing and antique turn of phrase could not be bettered for clarity, as examples will show.

Morgagni described the appendages attached to 10 testes and these have been reconstructed in diagrammatic form in Fig. 3, where it can be seen that they included both sessile and pedunculated types, attached to the testis and to the epididymis. Morgagni's discovery of them is an example of serendipity, for his interest was initially in the causes of hydroceles. He concluded that flat disclike 'corpuscles and excrescences' were ruptured versions of cystic forms which thus contributed to the fluid in the tunica vaginalis.

As early a writer as Griffiths (1894) considered the original terminology inappropriate, and suggested the term 'appendix' (of the testis or epididymis) for the non-cystic types of appendages. He stipulated that no spermatozoa were to be found in the appendix testis and appendix epididymis, thus distinguishing them from spermatoceles, and other cystic conditions of the epididymis.

It is convenient to refer to the clinical entity as

* Alexander, B. (1769). Seats and Causes of Diseases. [A translation of Morgagni, G. B., 1761. De Sedibus et Causis Morborum]. Miller and Cadell, London. 

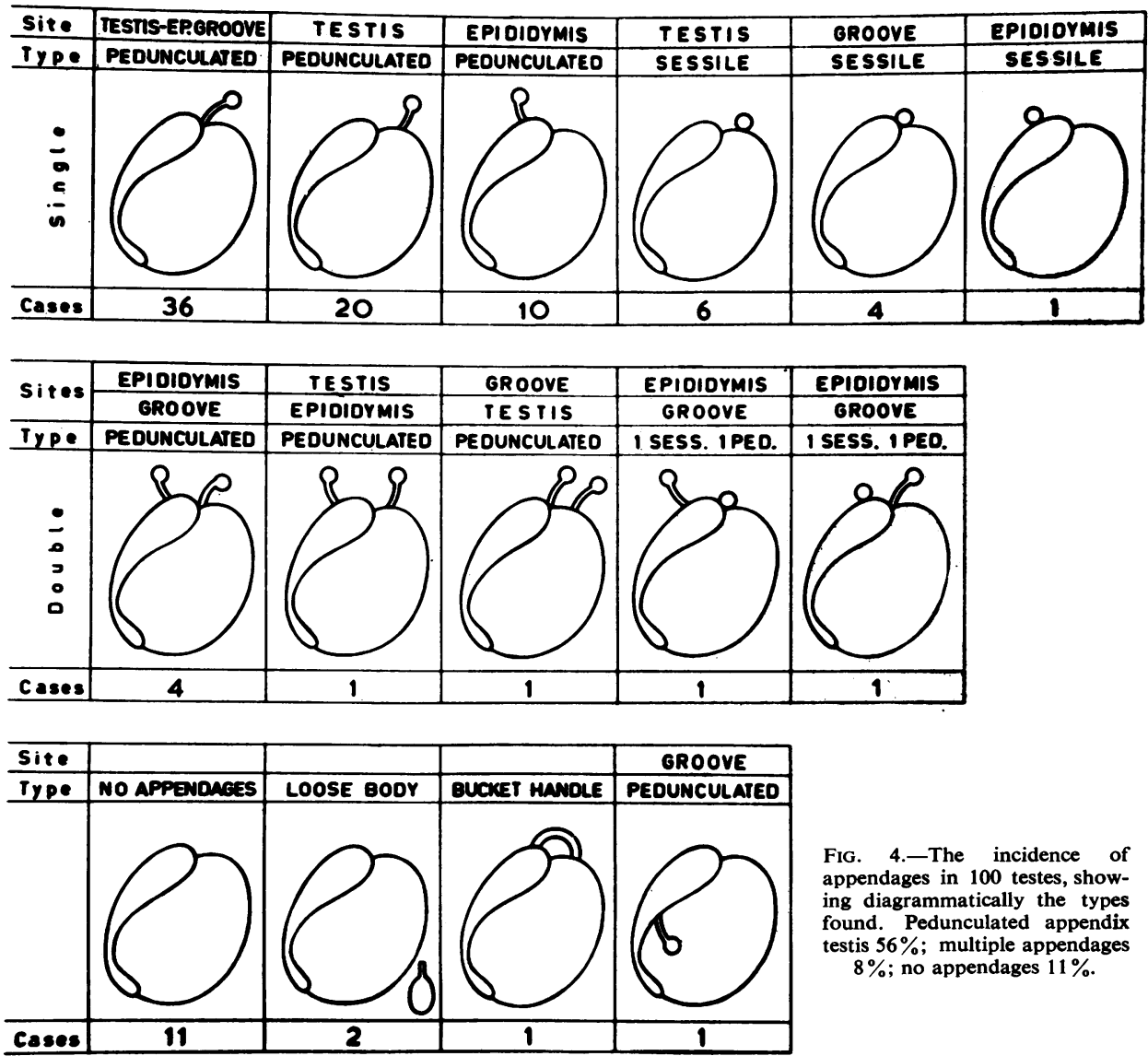

Fig. 4.-The incidence of appendages in 100 testes, showing diagrammatically the types found. Pedunculated appendix testis $56 \%$; multiple appendages $8 \%$; no appendages $11 \%$.

torsion of the hydatid of Morgagni, and to use Griffiths' term, the appendix testis, in describing anatomical detail.

\section{Incidence of Appendages in 100 Testes in Childhood}

In order to establish the incidence of appendages in children, 100 testes have been examined. The majority of these were pairs obtained at autopsy and the remainder were observed during life, in the course of operations for torsion, inguinal hernia and normally developed undescended testes (Fig. 4). It can be seen that the commonest type (36\%), was a single appendage attached to the groove between the globus major of the epididymis and the upper pole of the testis. Careful examination could not clearly determine whether the attachment was predominantly to one or the other.

One of Morgagni's original descriptions is as follows:

‘. . I observ'd a kind of small fimbria to be hanging from the albuginea where it invest'd the testicle, very near to the large globe of the epididymis, and this fimbria I judg'd to be a ruptur'd hydatid; especially as not far from this I perceiv'd an entire hydatid protruding from the same coat.'

Watson (1902) also noted the proximity of the attachment of the appendix testis to the groove between the testis and globus major.

No sound reason exists for perpetuating the confusing terminology which has evolved since Morgagni's time. It appears to have arisen from an incorrect conclusion that Morgagni described a pedunculated hydatid attached to the epididymis and a sessile hydatid attached to the testis. This error has produced such contradictory statements as 'the sessile hydatid of Morgagni which is paradoxically pedunculated'.

\section{Embryology}

The origin of the appendages has been the subject of some controversy, but the consensus is that the appendix testis is a persistent part of the parameso- 
nephric (Mullerian) duct, and that the appendix epididymis is the blind end of the mesonephric (Wolffian) duct (Hamilton, Boyd and Mossman, 1952; Johnston and Whillis, 1954). Less certain are the origins and nature of the vas aberrans (Lockwood, 1888) and the paradidymis or organ of Giraldès. Campbell (1951) confirms the extreme rarity of their clinical incidence and Fig. 4 shows the only vas aberrans found in 100 testes.

\section{Histology}

The normal appendix testis and appendix epididymis are of identical structure, being composed of loose fibrous tissue containing a few small blood vessels, the whole being covered by an epithelium which is usually low columnar, sometimes pseudostratified and occasionally ciliated. The appendix testis and the appendix epididymis occasionally contained tubular structures with a lining epithelium of columnar type which resembled that of the Fallopian tube. Vermeulen and Hagerty (1945) have noted these in the appendix testis.

As a consequence of torsion, the fibrous tissue becomes congested and infiltrated with polymorphonuclear leucocytes and lymphocytes. The epithelium is often lost from the surface.

The facts which emerge from a review of the literature can be summarized as follows:

(1) Morgagni described both cystic and noncystic, sessile and pedunculated appendages attached to the testis and to the epididymis.

(2) The terms 'appendix testis' and 'appendix epididymis' were introduced to describe the noncystic types of appendage which predominate.

(3) An appendage attached to the groove between the testis and the globus major is the commonest type of the appendix testis.

(4) Other types of appendages, the paradidymis and vas aberrans, are rarely encountered, but torsion of them has been recorded.

\section{Torsion of the Appendages}

Torsion of a testicular appendage was first recognized as a clinical entity by Colt (1922), a sursurprisingly recent recognition, for torsion of the testis was described 82 years earlier. Colt's publication prompted Shattock (1922) to report what has proved to be the only case of synchronous torsion of two appendages on record. A case reported by Ombrédanne (1913) was, in retrospect, considered to be one of torsion of the appendix testis. It remained for Mouchet (1923) to establish the clinical picture firmly in a series of nine publications between 1923 and 1928. Dix (1931) compiled a comprehensive list of reported cases and Randall

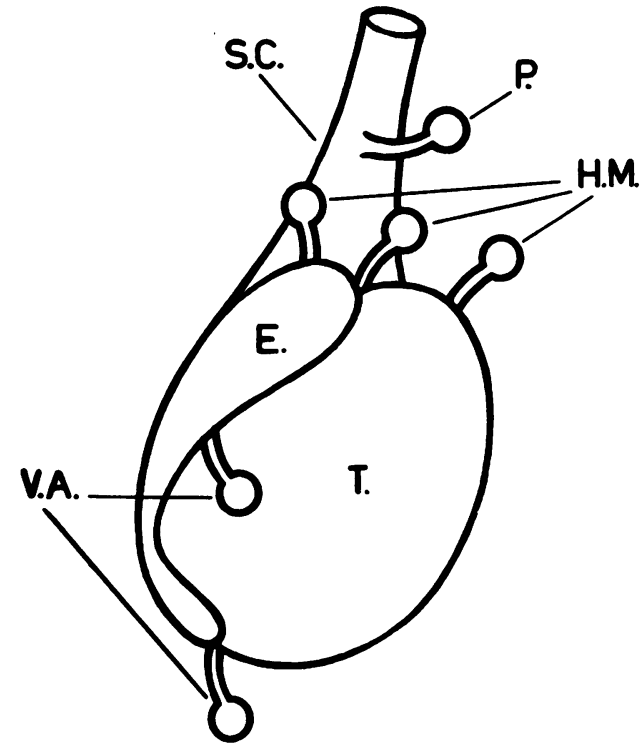

Fig. 5.-Types of appendage found in clinical reports of torsion (after Campbell).

S.C.: spermatic cord. E.: epididymis. T.: testis. P : paradidymis (Giraldès). H.M.: 'hydatid of Morgagni'. V.A.: vas aberrans.

(1939) brought the figures up to date. From these reviews it appeared that $64 \%$ of patients were between 10 and 14 years of age and only three were over 20. Both sides were affected with equal frequency; the sites of the appendages involved are shown in Fig. 5 and the numbers in Table 1.

TABLE 1

COLLECTED CASE REPORTS UP TO 1939 (RANDALL)

\begin{tabular}{|c|c|c|c|c|c|}
\hline \multicolumn{5}{|c|}{ Site } & \multirow{2}{*}{$\begin{array}{r}\text { Cases } \\
68 \\
2 \\
1 \\
2\end{array}$} \\
\hline $\begin{array}{l}\text { Torsion of appendix tes } \\
\text { Torsion of appendix epi } \\
\text { Torsion of paradidymis } \\
\text { Torsion of vas aberrans }\end{array}$ & $\begin{array}{l}\underset{y m}{\operatorname{yin}} \\
\cdots\end{array}$ & $\cdots$ & $\begin{array}{l}\cdots \\
\cdots \\
\cdots\end{array}$ & $\begin{array}{l}\cdots \\
\cdots \\
\cdots \\
\cdots\end{array}$ & \\
\hline Total & . & $\cdots$ & . & $\cdots$ & 73 \\
\hline
\end{tabular}

\section{CLINICAL MATERIAL}

Ten patients with torsion of the testis and nine patients with torsion of the hydatid of Morgagni were studied and are reported here (Tables 2 and 3).

The clinical features of the two conditions are considered separately and the differential diagnosis of each is discussed.

\section{Clinical Features of Torsion of the Testis}

Traditional accounts describe the sudden severe and prostrating pain, nausea, and vomiting which 
TABLE 2

TORSION OF THE TESTIS

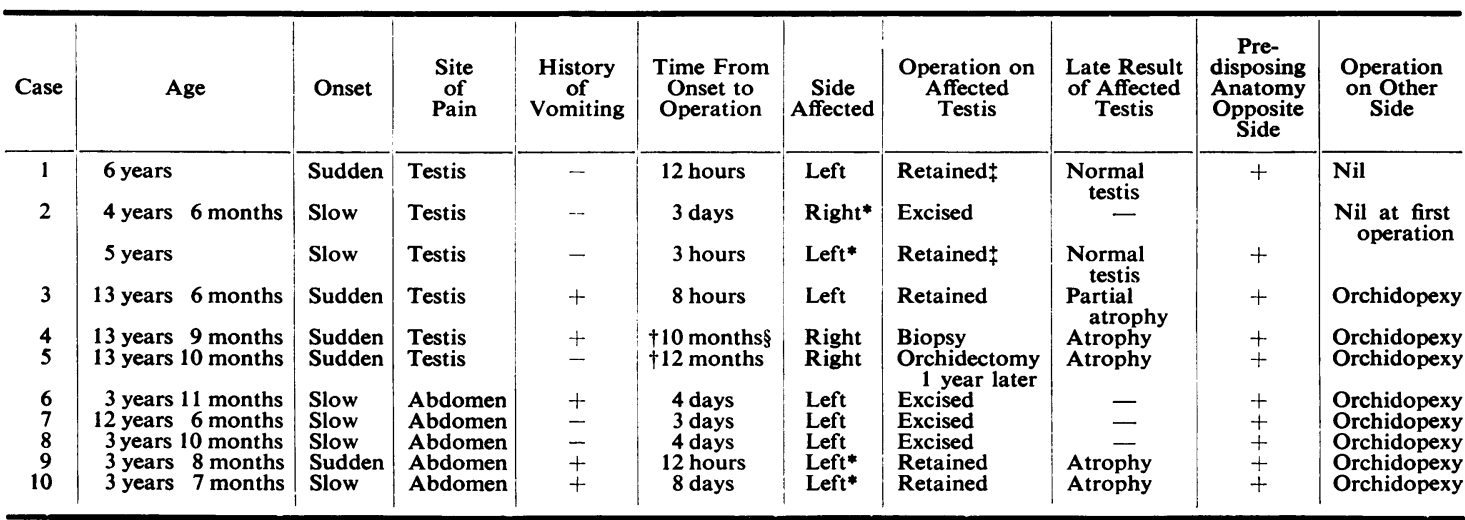

* Testis redux. $\quad$ Retrospective diagnosis. $\quad \ddagger$ Spontaneous untwisting. $\S$ 'Formes frustes' history.

TABLE 3

TORSION OF THE HYDATID OF MORGAGNI

\begin{tabular}{|c|c|c|c|c|c|c|c|c|}
\hline Case & Age & Onset & $\begin{array}{l}\text { Site } \\
\text { of } \\
\text { Pain }\end{array}$ & $\begin{array}{l}\text { History } \\
\text { of } \\
\text { Vomiting }\end{array}$ & $\begin{array}{l}\text { Time From } \\
\text { Onset to } \\
\text { Operation }\end{array}$ & $\begin{array}{c}\text { Side } \\
\text { Affected }\end{array}$ & $\begin{array}{l}\text { Operative Findings } \\
\text { Affected Side }\end{array}$ & $\begin{array}{l}\text { Operative Findings } \\
\text { Opposite Side }\end{array}$ \\
\hline 11 & 11 weeks & Sudden & $?$ & - & 4 hours & Left & Torsion appendix epidi- & Pedunculated appendix \\
\hline 12 & $\begin{array}{l}13 \text { years } 1 \text { month } \\
13 \text { years } 10 \text { months }\end{array}$ & $\begin{array}{l}\text { Slow } \\
\text { Slow }\end{array}$ & $\begin{array}{l}\text { Testis } \\
\text { Testis§ }\end{array}$ & - & $\begin{array}{l}4 \text { days } \\
2 \text { weeks; } \\
\text { attacks }\end{array}$ & $\begin{array}{l}\text { Right } \\
\text { Left }\end{array}$ & $\begin{array}{l}\text { No operation } \\
\text { Congested, red viable } \\
\text { pedunculated appendix }\end{array}$ & $\begin{array}{l}\text { Loose body at operation } \\
9 \text { months later }\end{array}$ \\
\hline 13 & 12 years & Slow & Abdomen & - & 2 days & Right & $\begin{array}{l}\text { Testis } \\
\text { Torsion appendix testis }\end{array}$ & Pedunculated appendix \\
\hline 14 & 11 years & Sudden & Testis§ & - & 16 hours & Left & Torsion appendix testis & Pedunculated appendix \\
\hline 15 & 10 years 6 months & Slow & Testis & - & 3 days & Left & Torsion appendix testis & Pedunculated appendix \\
\hline $\begin{array}{l}16 \\
17\end{array}$ & $\begin{array}{l}6 \text { years } \\
12 \text { years } 6 \text { months }\end{array}$ & $\begin{array}{l}\text { Slow } \\
\text { Slow }\end{array}$ & $\begin{array}{l}\text { Testis } \\
\text { Testis }\end{array}$ & - & $\begin{array}{l}14 \text { hours } \\
3 \text { days }\end{array}$ & $\begin{array}{l}\text { Left } \\
\text { Left }\end{array}$ & $\begin{array}{l}\text { No operation } \\
\text { Reflex oedema and red- } \\
\text { dening of epididymis; } \\
\text { small pedunculated ap- } \\
\text { pendix testis }\end{array}$ & $\begin{array}{l}\text { Pedunculated appendix } \\
\text { testis }\end{array}$ \\
\hline 18 & 6 years & Slow & Testis & - & 10 days & Right & $\begin{array}{l}\text { Torsion large appendix } \\
\text { testis; reflex changes in } \\
\text { epididymis }\end{array}$ & $\begin{array}{l}\text { Large pedunculated ap- } \\
\text { pendix testis }\end{array}$ \\
\hline 19 & 10 years & Slow & Testis & - & 12 hours & Left & $\begin{array}{l}\text { eplardymis } \\
\text { No operation }\end{array}$ & \\
\hline
\end{tabular}

$\S$ Formes frustes.

follow torsion of the testis. These descriptions are misleading in that they tend to paint a picture of great severity and sudden onset. It is important to realize that an undramatic onset is common, and that the slow appearance of testicular discomfort over several hours is quite compatible with torsion of the testis.

The details of the 10 patients with torsion of the testis are summarized.

Pain, Nausea and Vomiting. Pain was located in the testis in four patients. In five it was referred to the abdomen and steadily increased in severity, but in no instance did it resemble colic. In more than half of the patients the testis was not initially implicated, because of the abdominal site of the pain.

Nausea and anorexia were present in every patient, but vomiting occurred in only five out of the 10 , being severe in two and accompanied by marked pallor and prostration ('shock') in only one. The onset was sudden in four, but unspectacular in six.

Local Signs. Oedema of the scrotal skin appeared immediately after the onset; it increased for some hours, and appeared to reach a maximum in 12 to 24 hours. A tense hydrocele developed rapidly 
and was present within 12 hours of the onset in patients presenting sufficiently early.

Palpation was of little value, merely indicating exquisite tenderness and the presence of a tense hydrocele in which nothing could be distinguished.

Transillumination, apart from confirming the presence of a hydrocele, was similarly unrewarding.

Discoloration of the affected hemi-scrotum by a pink flush of hyperaemia was uniformly present within 12 hours and, with the scrotal oedema, produced the typical puffy pale pink scrotum. Oedema and tenderness extended some distance up the spermatic cord and was too variable to be of value in differential diagnosis.

The following cases illustrate special points.

Case 1. B.K., aged 6 years, was seen 12 hours after the sudden onset of pain in his left testis. He was nauseated and had noted that the scrotum was swollen and had become reddened in the last six hours. Examination showed an oedematous scrotum with a tender hydrocele surrounding the left testis. At exploration the testis was yellow in colour, with bruising of the tunica which contained clear fluid. The tunica vaginalis invested the cord and there was no posterior mesorchium. It was concluded that spontaneous reduction of the torsion had occurred before operation.

COMment. A normal testis after torsion has been the outcome in only two patients (Cases 1 and 2) and in both survival of the gonad was due to spontaneous reduction.

Case 2. L.R., aged 4 years 6 months, was operated upon four days after the onset of pain in the right testis which was gangrenous and therefore excised; no exploration of the left side was performed. Six months later pain in the left testis led to the child's admission to hospital within three hours. The scrotum was red and tender. At operation the testis was normal, but oedema of the cord, a hydrocele, and a high complete investment by the tunica, showed that a recent torsion had spontaneously reduced. Orchidopexy was performed.

Comment. Torsion of the opposite testis is of great importance when it follows gangrene of one testis. The predisposing abnormal anatomy was present and this boy was fortunate to have escaped castration. A similar case has been described by Adams and Slade (1958). It is significant that the predisposing features were present on the opposite side on each occasion on which it was explored (Campbell, 1951; Moulder, 1945; Johnson, 1960).

Case 4. A.B., aged 13 years and 9 months, was re-examined following 'epididymo-orchitis' of the left testis for which he had been admitted to hospital

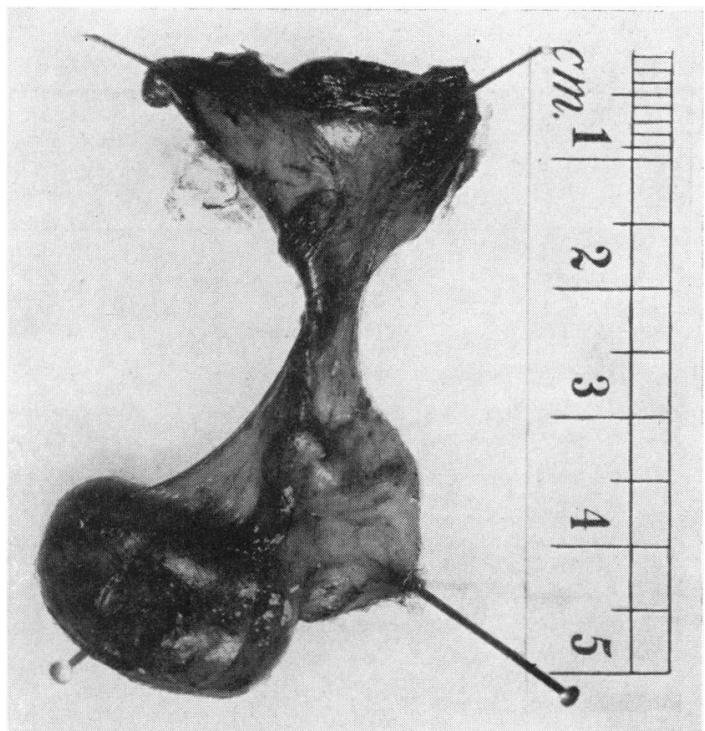

FIG. 6.-Testis excised 10 months after intratunical torsion and infarction. The tunica has been reflected upwards to show the site of torsion which is still identifiable (Case 5).

10 months earlier. The left testis was atrophic, hard, and devoid of testicular sensation. A review of the case notes of the first admission revealed that he had suffered recurrent attacks of severe pain in the left testis for two years. He had vomited several times on each occasion and was pale and 'shocked'; the left testis was swollen and acutely tender. On the basis of this history a retrospective diagnosis of torsion was made. The boy was readmitted and at operation through a median scrotal incision the left testis was found to be avascular and orange in colour. A biopsy subsequently showed the late picture of infarction. On the right side the tunica vaginalis extended $6.5 \mathrm{~cm}$. up the spermatic cord and the posterior mesorchium was absent. Eversion of the tunica and orchidopexy were performed.

Comment. This case and another (Case 5) were almost identical. It was possible to identify the site of torsion at operation one year later (Fig. 6).

Case 8. A.C., aged 3 years 10 months. For four days this boy suffered acute abdominal pain and displayed a left inguinal swelling which was diagnosed elsewhere as inguinal adenitis, and fomentations were applied. Subsequent examination determined that the left testis was absent from the scrotum; the inguinal swelling was $5 \mathrm{~cm}$. long and $3 \mathrm{~cm}$. wide, and was accompanied by oedema and reddening of the skin over the superficial inguinal pouch. Torsion of an undescended testis was diagnosed and exploration through an inguinal incision disclosed a gangrenous testis with intratunical torsion of the terminal $2 \mathrm{~cm}$. of the spermatic cord 
through $640^{\circ}$. The fundus of the tunica lay in the scrotum, and before excising the testis it was demonstrated that it could readily reach the bottom of the scrotum without freeing the cord. Orchidopexy of the right testis was performed through a median scrotal incision.

Comment. This is an example of testis redux, which occurred in four of the 10 torsions reported here. In two patients (Cases 9 and 10) the testis was drawn up to the neck of the scrotum. In one (Case 8), the testis was in the superficial inguinal pouch. If this point had not been appreciated at operation, the incorrect conclusion, i.e. that the testis was ectopic or incompletely descended, would have been reached.

It is quite possible that some cases of torsion which have been reported in undescended testes were in fact examples of testis redux.

\section{Clinical Picture of Torsion of the Hydatid of Morgagni}

Ten instances of torsion of the hydatid of Morgagni occurred in nine patients whose ages ranged from 11 weeks to 13 years (Table 3). Torsion of a pedunculated appendix testis was found in all except one, in which the appendix epididymis was involved. In one patient (Case 12) torsion of the appendix testis on both sides occurred.

Signs and Symptoms. The typical case can be summarized as follows: Pain in the affected testis, in no sense dramatic in onset, is at first not severe enough to interfere with normal activities. Nausea and vomiting do not occur. A hydrocele develops in the first 12 to 24 hours, but usually does not become too tense for accurate palpation until some 36 hours later. By the second day the scrotum has become oedematous and presents a watery, pink appearance. Tenderness and discomfort increase and by the third day make walking difficult. Most of the patients are afebrile throughout. In one patient the pain was initially referred to the lower portion of the abdomen and its origin was not appreciated until scrotal swelling appeared on the second day. In another the onset was sudden but symptoms were mild.

'Formes frustes' (Mouchet, 1923), recurrent premonitory and self-reducing episodes of torsion were noted in two of the nine patients.

The following patients presented interesting features:

Case 11. G.O'H., aged 11 weeks. The scrotum was normal when his napkin was changed at 2 p.m. At 5.30 p.m. the left half of the scrotum was swollen and pink; he was restless and he cried continually. There was a tense hydrocele which prevented accurate palpation of the testis. Exploration through a median scrotal incision revealed a torsion of the left appendix epididymis. On the right side a normal appendix epididymis was found and removed.

COMment. This is the only case in which torsion of the appendix epididymis was found. The secondary hydrocele developed with unusual rapidity, and torsion of the testis could not be excluded before operation.

Case 12. H.B., aged 13 years and one month, presented with mild pain in the right testis which had been present for four days. There was slight swelling and redness in the right hemi-scrotum which contained a lax hydrocele. Palpation and transillumination of the testis occasioned no pain, but attached to its upper pole was a tender purple spherical body some $5 \mathrm{~mm}$. in diameter. A diagnosis of torsion of the appendix testis was made; all signs subsided in the course of a few days. Ten months later the boy returned having had two similar attacks of pain in the left testis. Each lasted a few hours and was accompanied by some swelling in the left half of the scrotum. Examination revealed no abnormality. The attacks were considered to be 'formes frustes' of torsion of the appendix testis, but incomplete torsion of the testis could not be excluded. Exploration was readily agreed upon, and on the left side a bright red congested but viable appendix testis $4 \mathrm{~mm}$. diameter was removed through a median scrotal incision. In the right tunica vaginalis there was a hard, yellow oval disc measuring $5 \mathrm{~mm}$. by $3 \mathrm{~mm}$. lying free near the lower pole of the testis. This without doubt represented the right appendix testis which had undergone torsion 10 months before.

Comment. It is interesting that Morgagni found the same type of loose body at autopsy in April 1740 on a man 'who fell from a high place', and who had a hydrocele.

. . . But as I happen'd to observe that while the water that surround'd it was discharg'd, a little body, of some kind or other, had come out therewith, I found, by looking into this water, a corpuscle of the bigness of a small grape, and the shape also; except that this little body, inclining somewhat to the oval figure, had, in the middle of one extremity, a short and slender neck, as it were; so as to resemble a very small bottle, or if you please a grape still furnish'd with a stalk, and that of the same substance with the grape. And indeed this corpuscle seem'd to have adher'd to some part, by its neck or stalk; and being shaken off by some cause or other, to have fallen into the water ... The substance whereof it constitut'd, internally and externally, was white, dense and compact; if you except a very small part of an irregular figure, which occupied the middle place, and seem'd to be a kind of nucleus. For this part was yellowish, and almost of a bony hardness; whereas every other part, when press'd betwixt the fingers gave way in some measure.' (Epistola XLIII, p. 25). 


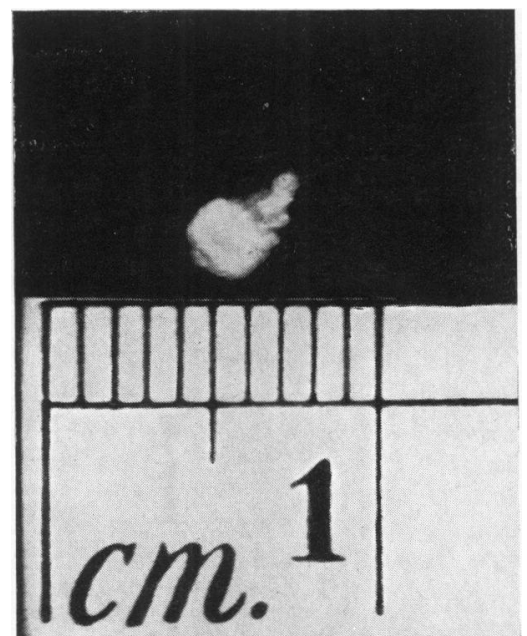

Fig. 7.-Calcareous loose body found in the tunica vaginalis. The shape of the appendage and its pedicle are preserved.

Contiades and Mérigot (1932) found loose bodies in hydroceles in two patients. In each case the relevant testis was devoid of appendages, and though neither patient had a definite history of torsion, the authors considered this to be the precursor. In support they quoted several authorities, among them Astley Cooper, Volkmann and Kocher.

An identical loose body was found at autopsy on a 12-year-old boy (Fig. 7).

Case 16. R.F., aged five years, a surgeon's son, was seen 16 hours after the slow onset of mild pain in the right testis. There was no oedema or reddening of the scrotum, but a small lax hydrocele was present. Palpation combined with transillumination detected a small tender nodule attached to the upper pole of the testis but separate from it. A diagnosis of torsion of the appendix testis was made, and the patient observed daily. On the fourth day the hydrocele had become so tense that it precluded all testicular findings. If this had been the initial examination torsion of the testis could not have been excluded. Conservative management was accompanied by distressing reflex urethral hyperalgesia, and in retrospect this period of discomfort might have been shortened by excision of the twisted appendage.

Comment. Operation to relieve symptoms has been advocated by Randall (1939). When the diagnosis is certain and the symptoms mild, there seems little reason to substitute a week of postoperative swelling for seven days of progressive spontaneous resolution. If after two days the symptoms are still severe, it seems reasonable to operate.
Case 17. K.D., aged 12 years and 6 months, was seen three days after the slow onset of pain in the left testis. On the second day the scrotum was red and swollen, and the tenderness had greatly increased. A tense left hydrocele was present and exploration through a median scrotal incision showed the globus major of the epididymis to be extremely hyperaemic. The testis was normal in size and colour. A presumptive diagnosis of epididymitis was made, and an appendix testis $4 \mathrm{~mm}$. in length removed from each side. The left appendix testis was grey in colour, while the right was the usual pale pink. Microscopic examination showed the left appendage to be infarcted. The final diagnosis was torsion of the appendix testis.

Comment. It is assumed that torsion produced a localized reflex hyperaemia. Ombrédanne (1913), Mouchet (1923) and Patch (1933), among others, noted identical changes in the epididymis accompanying torsion of the appendix testis. When the appendix testis is small and its change in colour is unspectacular, epididymitis could readily be misdiagnosed, even after exploration.

Case 19. D.M., aged 10 years 3 months, was operated on for an ectopic left testis in the superficial inguinal pouch. Orchidopexy was performed by suturing the tunica albuginea to the scrotal skin. The convalescence was uneventful. Three months later pain began in the same testis and when examined 12 hours after the onset the typical pink oedema of torsion was present. Maximal tenderness was at the upper pole of the testis which lay within a moderately tense hydrocele. Torsion of the hydatid of Morgagni was diagnosed because fixity of the lower pole of the testis excluded torsion of it. All swelling had subsided at the end of the week without operation. The testis was apparently normal when examined six months later.

COMMENT. Orchidopexy conveniently excluded torsion of the testis and the symptoms were mild. Fèvre and Bureau (1929) reported a similar case proved by re-exploration four months after orchidopexy. It is reasonable to remove the appendages during operations on undescended testes, though subsequent torsion of an appendage is very rare.

\section{DIFFERENTIAL DIAGNOSIS}

Three conditions which may present very similar clinical findings are:

Torsion of the testis

Torsion of the hydatid of Morgagni

Epididymo-orchitis

The differentiation of these may be difficult and is often impossible without surgical exploration.

\section{Torsion of the Testis}

The onset is more likely to be sudden, accompanied by vomiting and referred abdominal pain, 
but these features are inconstant and may be absent, especially in infants. Testis redux may simulate a strangulated inguinal hernia; in this event the vomiting and abdominal pain of torsion may be especially misleading. Absence of the testis from the scrotum on the affected side provides a clue that it may be involved. It may be undescended or the site of redux.

Torsion of the hydatid of Morgagni in an ectopic testis in the superficial inguinal pouch can also produce a similar inguinal swelling.

During infancy, and particularly in the newborn, a strangulated indirect inguinal hernia is not infrequently accompanied by infarction of the testis (Sloman and Mylius, 1958), due to the anatomical arrangement of the testicular vessels. The spermatic cord is often intrasaccular, lying in a mesentery within the wall of the hernia, and is thus vulnerable to pressure by its contents. Fortunately, strangulated hernia most frequently presents as an inguinal mass separate from the testis and scrotum, but continuity of the hernial sac with the tunica vaginalis is quite common in infancy, and when this anatomical arrangement exists only exploration can clarify the situation.

A further difficulty is presented by the condition known as 'spontaneous haemorrhagic infarction' of the testis which may occur in the newborn or even at birth. The clinical picture is that of torsion of the testis, but apparently at operation it may not be possible to demonstrate torsion (James, 1953; Glaser and Wallis, 1954; Longino and Martin, 1955).

\section{Torsion of the Hydatid of Morgagni}

In favourable circumstances the diagnosis can be made on palpation of a small tender nodule attached to the upper pole of the testis. In a number of patients a secondary hydrocele obscures the findings and exploration is required.

\section{Epididymo-orchitis}

Several varieties occur, some following chronic renal tract infection, some due to mumps, and a third miscellaneous group in which funiculitis may be included.

Urinary Tract Infection. As a rule epididymoorchitis follows chronic pyobacilluria which is in turn often due to abnormalities of the renal tract, such as mega-ureter or vesico-ureteric reflux. This type of epididymo-orchitis may be bilateral or recurrent, and diagnosis does not usually present a problem.

Mumps Orchitis. After puberty orchitis is a common complication of mumps, the incidence varying from $16 \%$ to $64 \%$ in different epidemics. In the prepubertal years orchitis is less common. The current figures at Queen's Memorial Infectious Diseases Hospital in Melbourne show an incidence of $18 \%$. This figure is possibly higher than the overall incidence because of the selective admission of severe cases. In half of these patients orchitis appeared at the same time as the parotitis; in half it developed immediately after.

On rare occasions orchitis is the only manifestation of mumps. Connolly (1953) has ably discussed this aspect. The clinical appearance of the scrotum and testes in mumps orchitis is in no way distinctive, apart from the fact that both testes are frequently affected.

Miscellaneous Group. Infections elsewhere in the body occasionally spread to the epididymis and testis. Staphylococcus albus and aureus have been isolated from the tunica vaginalis in these cases, from abscesses in the epididymis, and from the primary extragenital sites.

There remains a group of patients in which exploration confirms the diagnosis of epididymoorchitis but fails to indicate its cause. Funiculitis, an inflammatory oedema of the spermatic cord and its coverings, is sometimes found. This, too, is of unknown origin, and sporadic funiculitis of this type bears no relation to the lethal epidemic form which is described in the textbooks.

\section{ROYAL CHILDREN'S HOSPITAL SURVEY}

To provide a broad representative picture, the case notes of patients admitted with acute testicular conditions have been examined. Between 1950 and 1960 , there were 95 cases of torsion and epididymoorchitis. The three conditions with appropriate sub-headings are set out in Table 4 . Patients with mumps seen at the Royal Children's Hospital are transferred to the Queen's Memorial Infectious Diseases Hospital if they require admission.

\section{Epididymo-orchitis (25 cases)}

Urinary tract infections and extragenital sepsis were found in approximately half the cases. Those due to unknown causes formed the largest group, and it is possible that some of these were mumps orchitis without parotitis. A rising antibody titre might be useful in the investigation of future patients.

\section{Torsion of the Hydatid of Morgagni (25 cases)}

The figures confirm the statement that both testes are affected equally (right: 12 ; left: 11). 
TABLE 4

PATIENTS ADMITTED TO ROYAL CHILDREN'S HOSPITAL, MELBOURNE, WITH ACUTE CONDITIONS OF THE TESTIS, 1950-1960

\begin{tabular}{|c|c|c|c|c|c|c|c|c|}
\hline \multicolumn{4}{|c|}{ Torsion of Testis } & \multicolumn{3}{|c|}{ Torsion of Appendages } & \multicolumn{2}{|c|}{ Epididymo-orchitis } \\
\hline Type & No. & Site & No. & Site & & No. & Cause & No. \\
\hline $\begin{array}{l}\text { Intratunical } \\
\text { Extratunical } \\
\text { Uncertain }\end{array}$ & $\begin{array}{l}5 \\
3\end{array}$ & $\begin{array}{l}\text { Descended (testis redux, 6) } \\
\text { Undescended } \\
\text { Uncertain }\end{array}$ & 33 & $\begin{array}{l}\text { Appendix testis } \\
\text { Appendix epidid } \\
\text { Vas aberrans }\end{array}$ & $\begin{array}{l}\text { Right } \\
\text { Left } \\
\text { is }\end{array}$ & $\begin{array}{r}12 \\
11 \\
1 \\
1\end{array}$ & $\begin{array}{l}\text { Urinary tract infection } \\
\text { General sepsis } \\
\text { Funiculitis } \\
\text { Unknown causes }\end{array}$ & $\begin{array}{r}6 \\
6 \\
3 \\
10\end{array}$ \\
\hline \multicolumn{3}{|c|}{ Totals (left 31 ; right 14 ) } & 45 & & & 25 & & 25 \\
\hline
\end{tabular}

I am indebted to Mr. F. Douglas Stephens for his permission to report the following unusual case:

T.B., aged 4 years 10 months, complained of pain in the left testis of 12 hours' duration. On examination the scrotum on that side was oedematous and hyperaemic. He was afebrile. At operation the testis was normal, with a round congested mass $(1 \mathrm{~cm}$. in diameter) attached to its lower pole by a short narrow pedicle. This was removed and microscopic examination showed typical changes of torsion with 'the vas' present in the section.

This appears to be only the third report of torsion of a vas aberrans, though Campbell (1951) mentions the possibility of others unpublished.

\section{Torsion of the Testis (45 cases)}

The relative frequency of this condition is perhaps surprising, for the number of patients with torsion of the testis almost equals the sum of all those suffering from other acute testicular conditions.

The patients are grouped according to the diagnosis and to age in Table 5.

TABLE 5

PATIENTS WITH ACUTE TESTICULAR CONDITIONS ARRANGED IN AGE GROUPS (R.C.H., 1950-1960)

\begin{tabular}{cc|c|c|c}
\hline Age & $\begin{array}{c}\text { Torsion of } \\
\text { Testis }\end{array}$ & $\begin{array}{c}\text { Torsion of } \\
\text { Hydatid of } \\
\text { Morgagni }\end{array}$ & $\begin{array}{c}\text { Epididymo- } \\
\text { orchitis }\end{array}$ \\
\hline $\begin{array}{c}\text { Birth to 1 year } \\
1-5 \text { years }\end{array}$ & $\cdots$ & 11 & 0 & 9 \\
$\begin{array}{c}5-10 \text { years } \\
10-15 \text { years }\end{array}$ & $\cdots$ & 8 & 4 & 6 \\
\hline Total & $\cdots$ & 45 & 16 & 3 \\
\hline
\end{tabular}

Testis redux was observed in seven patients and was possibly unrecognized in several others.

Spontaneous reduction of the torsion appeared to occur before exploration in six patients.

Intratunical torsion occurred in 37 patients, and extratunical torsion in five, of which four were infants, in one of whom the testis was undescended.
The fifth patient with extratunical torsion was a 13-year-old boy in whom a fully descended testis was affected. In three cases the case notes were inadequate, and the type of torsion could not be determined.

In seven patients the testis was 'undescended', and in five others it may have been so but the possibility of testis redux made these difficult to classify.

Six of the seven undescended testes underwent intratunical torsion; only one was extratunical.

There were 11 cases of torsion of the testis in infancy. Seven were fully descended and of these four were extratunical, and three were indeterminate in type. In four infants the torsion was intratunical and occurred in an undescended testis.

\section{DISCUSSION}

This study has emphasized the difficulty in reaching a clinical diagnosis.

Torsion of the testis is a most serious condition and exploration at the earliest possible moment is required if the testis is to be preserved.

Epididymo-orchitis is the most dangerous misdiagnosis if it is followed by non-operative treatment, for torsion of the testis may be present. Except in those patients in whom there are strong contraindications to operation, a diagnosis of epididymo-orchitis should be confirmed by exploration.

Torsion of the hydatid of Morgagni is the least serious condition for gangrene of the appendage produces no long-term disability except, rarely, a hydrocele. Frequently torsion of the testis cannot be excluded and exploration is indicated.

\section{Treatment of Torsion of the Testis}

External 'detorsion' (sic) by manipulation must play a very small role, perhaps only in those patients presenting very soon after the onset. It was certainly applicable to none of the patients reported here. Though recommended by some authors (Donovan, 1930; Burkitt, 1956; Chambers, 1956), 
and though, on occasion, apparently successful, it must be condemned on the following grounds:

(1) It can be attempted in a few early cases only.

(2) Complete success must always be a matter of conjecture.

(3) It does nothing to prevent recurrent attacks which lead to atrophy (O'Conor, 1933; Blandy, 1957).

(4) The omission of contralateral orchidopexy is a serious disadvantage (Johnson, 1960).

Surgical Exploration. There is no time limit beyond which operative reduction is not worth while, for spontaneous untwisting and recurrence of torsion can occur. A testis has proved to be gangrenous five hours after the onset of torsion, while a viable testis has been found after 36 hours. Operation should be undertaken in all cases.

Exploration of a testis in the scrotum is most conveniently performed through a midline scrotal incision. When 'testis redux' is present and the testis is in the superficial inguinal pouch, a transverse inguinal incision in the skin crease is appropriate.

When viability of the testis is in doubt, the application of hot saline packs for a few minutes may aid the return of blood supply. A small incision in the tunica albuginea, if productive of arterial bleeding, may be a further guide. On the whole conservatism is justified for should doubt persist the testis can be returned to the scrotum without fear of ischaemic pain or sepsis as sequelae. Subsequent atrophy may be less than might be expected. When necrosis is certain the testis is best removed.

Of especial importance is exploration and orchidopexy of the opposite testis. The predisposing anatomical factors of intratunical torsion are frequently present on both sides, and torsion of the second testis is common enough to demand prevention. A technique which has proved effective is eversion of the tunica vaginalis and placement of a fine chromic suture at each pole of the testis, passing through the scrotal skin, where each is tied externally over a roll of vaseline gauze.

\section{Treatment of Torsion of the Hydatid of Morgagni}

A median scrotal incision again provides ready access to the testis, which is delivered from the tunica and the twisted appendage excised. The tiny pedicle does not bleed as a rule and ligature of it is usually unnecessary. It is a small matter to open the contralateral tunica and remove any appendages found there. The chance of torsion of an appendage on the second side is admittedly very small; but a few moments suffice to eliminate the possibility.

\section{CONCLUSIONS}

From the series of patients reported and the data obtained from the Royal Children's Hospital records the following conclusions have been reached.

(1) Torsion of the testis is the commonest cause of painful, swollen and tender scrotum in infancy and childhood.

(2) Torsion most frequently affects fully descended testes, and is intratunical in type.

(3) Torsion of undescended testes, often associated with an indirect inguinal hernia, is usually intratunical or, more accurately, intrasaccular.

(4) Torsion of undescended testes is more common in infancy than in older children.

(5) Extratunical torsion is more common in infancy than in older children, and in most cases the testis is fully descended.

(6) The left testis is affected by torsion much more frequently than the right (left: 31 patients; right: 14 patients).

(7) Torsion of the testis occurs with equal frequency throughout infancy and childhood, whereas torsion of the hydatid of Morgagni is rare in infancy and there is a sharp increase in incidence in children over 10 years of age.

(8) The average duration of torsion of the testis before operation was 51 hours. The diagnosis is frequently delayed beyond the point of recovery of the testis. This delay may be in seeking medical advice, especially when symptoms are mild. Further delay may result from uncertainty of the diagnosis or the too ready acceptance of an alternative such as epididymo-orchitis. Earlier exploration should result in a greater number of viable testes.

(9) The high incidence of factors predisposing to torsion of the contralateral testis make orchidopexy mandatory. Torsion of both testis, at different times, occurred in three boys. The initial experience acquainted their parents with the nature of the emergency and led to immediate admission and a satisfactory outcome in each case.

\section{SUMMARY}

The anatomy, histology, pathology and clinical features of torsion of the testis and its appendages are described.

The original historical descriptions and the literature are reviewed.

A series of 10 patients with torsion of the testis 
and nine patients with torsion of the hydatid of Morgagni is presented in detail.

The differential diagnosis is discussed and treatment described.

An estimate of the relative frequency of the conditions has been made from the case records of patients admitted to the Royal Children's Hospital between 1950 and 1960 .

I would like to express my gratitude to my colleagues on the staff of the Royal Children's Hospital for permission to consult their case records, and the Queen's Memorial Infectious Diseases Hospital for permission to quote their figures. It is a pleasure to acknowledge the help of Dr. Reginald Webster, Burton Research Fellow in Pathology, for his correction of the final draft, and the excellent work of Mr. Thake and Mr. Murphy in the preparation of the illustrations.

\section{REFERENCES}

Abeshouse, B. S. (1936). Torsion of spermatic cord; report of three cases and review of the literature. Urol. cutan. Rev., 40, 699

Adams, A. W. and Slade, N. (1958). Torsion of the testis and its treatment. Brit. med. J., 1, 36

Allen, P. D. and Andrews, T. H. (1940). Torsion of the spermatic cord in infancy. Amer. J. Dis. Child., 59, 136.

Blandy, J. P. (1957). Three cases of torsion of the testis. Brit. med. J. $1,807$.

Browne, D.' (1938). The diagnosis of undescended testis. ibid., $2,168$.

Burkitt, R. (1956). Torsion of the spermatic cord; a plea for manipulative reduction. ibid., 2,345

Campbell, M. (1951). Clinical Pediatric Urology. Saunders, Philadelphia.

Chambers, D. G. (1956). Torsion of the spermatic cord. Brit. med. $J ., 2,552$.

Colt, G. H. (1922). Torsion of the hyatid of Morgagni. Brit. J. Surg., $9,464$.

Connolly, N. K. (1953). Mumps orchitis without parotitis in infancy. Lancet, 1, 69.

Contiades, X. J. and Mérigot, L. (1932). À propos de deux cas d'hydrocèle secondaire à la torsion de l'hydatide de Morgagni. Ann. anat. path., 9, 795.

Delasiauve, - (1840). Descente tardive du testicule gauche, prise pour une hernie étranglée. Rev. méd. franc. ét etrangère, 1,363

Dix, V.W. (1931). On torsion of the appendages of the testis and the epididymis. Brit. J. Urol., 3, 245.

Donovan, E. J. (1930). Torsion of the spermatic cord in infancy. Ann. Surg., 92, 405.

Ewert, E. E. and Hoffman, H. A. (1944). Torsion of the spermatic cord. J. Urol. (Baltimore), 51,551 .

Fèvre, - and Bureau, R. (1929). Torsion d'une hydatide de Morgagni dans un cas de testicule éctopique opéré par orchidopexie. Ann. anat. path., 6, 694

Glaser, S. and Wallis, H. R. E. (1954). Torsion or spontaneous haernorrhagic infarction of the testicle in the newborn infant. Brit. med. J., 2, 88.
Griffiths, J. (1894). Observations on the appendix of the testicle, and on the cysts of the epididymis, the vasa efferentia, and the rete testis. J. Anat. (Lond.), 28, 107.

Hamilton, W. J., Boyd, J. D. and Mossman, H. W. (1952). Human Embryology. 2nd ed. Heffer, Cambridge.

James, T. (1953). Torsion of the spermatic cord in the first year of life. Brit. J. Urol., 25, 56.

Johnson, N. (1960). Torsion of the testis-a plea for bilateral exploration. Med. J. Aust., 47, 653 .

Johnston, T. B. and Whillis, J. (1954). Gray's Anatomy, 31st ed. Longmans, Green, London.

Jones, P. G. (1958). The superficial inguinal pouch and the undescended testis. Med. J. Aust., 1, 239.

Lambert, J. and Smith, R. E. (1937). Torsion of the testicle and of the hydatid of Morgagni. Brit. J. Surg., 25, 553.

Lockwood, C. B. (1888). The development and transition of the testis, normal and abnormal. J. Anat. (Lond.), 22, 38.

Longino, L. A. and Martin, L. W. (1955). Torsion of the spermatic cord in the newborn infant. New Engl. J. Med., 253, 695.

Lowsley, O. S. and Kirwin, T. J. (1944). Clinical Urology, 2nd ed. Williams and Wilkins, Baltimore.

Meltzer, M. (1926). Torsion of the testicle. J. Urol. (Baltimore), 15, 601 .

Morgagni, G. B. (1761). De Sedibus et Causis Morborum. Bassano, Padua. Translated by B. Alexander (1769). Seats and Causes of Diseases. Miller and Cadell, London.

Mouchet, A. (1923). Sur une variété d'orchite aiguë de l'enfance, due a une torsion de l'hydatide de Morgagni. Presse méd., due 485 .

Moulder, M. K. (1945). Bilateral torsion of the spermatic cord. Urol. cutan. Rev., 49, 354

Muschat, M. (1932). The pathological anatomy of testicular torsion; explanation of its mechanism. Surg. Gynec. Obstet., 54, 758.

Myers, N. A. (1961). Torsion of the spermatic cord in the neonatal period, with report of a case. Med. J. Aust., 2, 793.

O'Conor, V. J. (1919). Torsion of the spermatic cord. Surg. Gynec. Obstet., 29, 580.

- (1933). Torsion of the spermatic cord. ibid., 57, 242.

Ombrédanne, L. (1913). Torsions testiculaires chez les enfants. Bull. Soc. Chir. Paris, 39, 779.

Patch, F. S. (1933). Pedunculated cysts within the tunica vaginalis, with report of a case showing torsion of the pedicle. Brit. J. Urol., 5, 122 .

Peterson, C. G. (1961). Testicular torsion and infarction in the newborn. J. Urol. (Baltimore), 85, 65.

Randall, A. (1939). Torsion of the appendix testis (hydatid of

Morgagni). ibid., 41, 715.
Rigby, H. M. and Howard, R. J. (1907). Torsion of the testis. Lancet, 1, 1415 .

Shattock, C. E. (1922). A case of torsion of the hydatids of Morgagni. ibid., 1, 693 .

Sloman, J.' G. and Mylius, R. E. (1958). Testicular infarction in infancy: its association with irreducible inguinal hernia. Med. J. Aust., 1, 242

Taylor, M. R. (1897). A case of testicle strangulated at birth: castration: recovery. Brit. med. J., 1, 458.

Vermeulen, C. W. and Hagerty, C. S. (1945). Torsion of the appendix testis (hydatid of Morgagni): a report of two cases with a study of the microscopic anatomy. J. Urol. (Baltimore), 54, 459.

Watson, J. H. (1902). Some observations on the origin and nature of the so-called hydatids of Morgagni found in men and women, with especial reference to the fate of the Müllerian duct in the epididymis. J. Anat. (Lond.), 36, 147.

Williams, D. I. (1958). Handbuch der Urologie. [Encyclopedia o Urology.] Vol. 15, p. 264, ed. C. E. Alken, et al. Springer, Berlin.

Young, H. H. and Davis, D. M. (1926). Practice of Urology. Saunders, Philadelphia. 